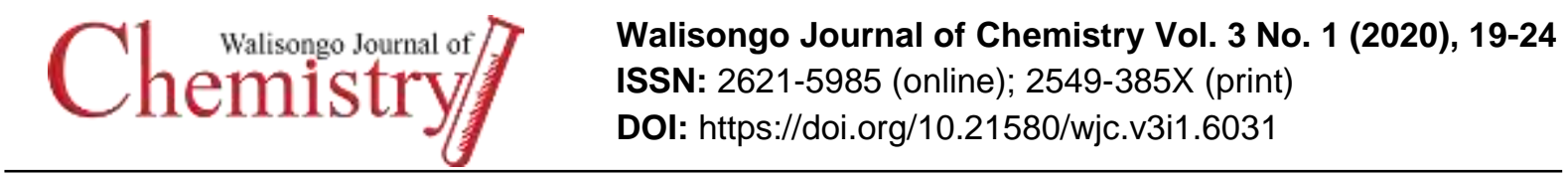

\title{
Transformation of Vanillin into Octahydroxanthene Derivative Using Guanidine Catalyst
}

\author{
Moch Abdussalam¹, Indah Permata Yuda1, Juniarti*2 \\ ${ }^{1}$ Herbal Research centre, Yarsi University, Jakarta, 10510, Indonesia \\ 2Biochemistry Departement, Faculty of Medicine, Yarsi University, Jakarta, 10510, \\ Indonesia \\ e-mail: *2juniarti@yarsi.ac.id
}

\begin{abstract}
Octahydroxanthene Compounds are bioactive substance which can be produced from benzaldehyde derivative. In this research, we have carried out transformation of vanilin from Indonesian natural product to octahydroxanthene derivatives compound at optimized reaction time and guanidine was used as a catalyst. Several spectroscopy methods such as IR, $1 \mathrm{H}-\mathrm{NMR}$ and GC-MS were used to confirm the structure of product. The percent yield from optimation product obtained was $91 \%$ with $96 \%$ of peak area.
\end{abstract}

Keywords: octahydroxanthene; vanilin; transformation.

\section{Introduction}

Indonesia has a lot of biodiversity, especially in the tropical rainforest group. Tropical plants are found in almost all species of plants spread throughout the archipelago ranging from Sumatra, Kalimantan, Java, Sulawesi and Irian. Plants in Indonesia are not only functionally used as food, ornamental plants, but can also be used as medicinal plants that have many functions. Natural chemical compounds contained in plants in the form of primary and secondary metabolite compounds obtained through metabolic processes. Secondary metabolite compounds consist of alkaloids, terpenoids, steroids, flavonoids and polyketides (Dewick, 2009). The existence of secondary metabolites is highly dependent on the type of plant. This is why plants have been used as medicines for hundreds or even thousands of years ago. Among the natural products of tropical plants are vanillin from the vanilla tree, cinnamaldehyde from cinnamon bark, eugenol from clove fruit, anetol from fennel fruit and curcumin from turmeric rhizome (Matsjeh, 2009). Vanilla (Vanilla planifoliaI) is a plant that grows in Indonesia which has a high economic value because it contains vanillin with a large enough concentration. Indonesia is one of the largest vanillin producing countries in the world. The use of vanillin is limited to flavor (Risnandar et al, 2019) and products need to be developed that have greater benefits (Sofyaningsih et al, 2009). Vanillin is a natural phenolic derivative which generally has a unique bioctivity.

In addition, this compound has an aromatic aldehyde group that has the potential to be transformed into another compound that is more active in terms of bioactivity against various bioassay tests. One of the 
opportunities for the transformation of vanillin compounds is by conducting condensation with 1,3-ketone compounds so that octahydroxanthene derivatives are formed (Cahyana et al, 2018). Octahydroxanthene derivative compounds are heterocyclic groups with interesting oxygen atoms in terms of biochemistry (Moghanian et al, 2014), because they have activities, as actibacterial, anti-inflammatory and antioxidant. The transformation of vanillin into a compound with a dihydroxyxanthene framework is expected to increase the power and variety of bioactivity tests. Synthesis of octahydroxanthene compounds can be done by various methods including using heterogeneous catalysts (Bhat et al, 2016) (Dabiri et al, 2008) and homogeneous catalysts (Magar et al, 2018).

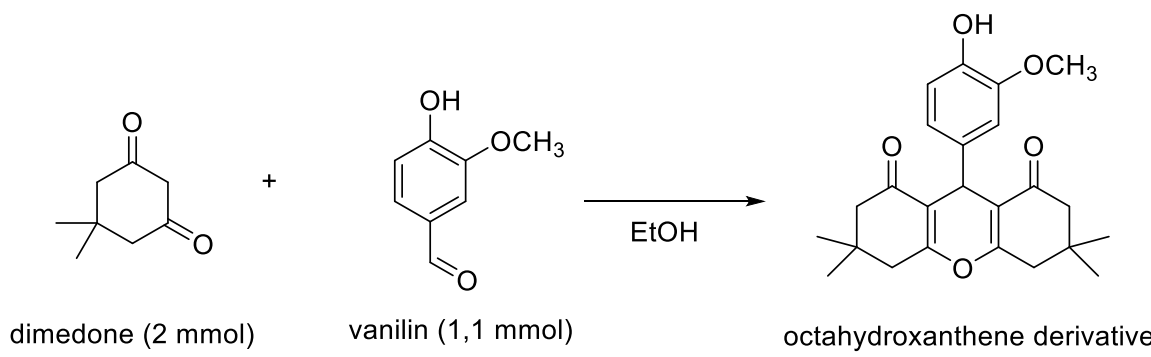

Figure 1. Transformation of vanillin into octahydroxanthene

\section{Experimental}

The chemicals used in this transformation were vanillin, dimedone, guanidine, $\mathrm{HCl}$ and ethanol. These materials were obtained from Merck, with proanalysis grade. The progress of the transformation is monitored using $0.2 \mathrm{~mm}$ thin layer chromatography silica gel F-254 (Merck). Infrared spectroscopy was measured by FTIR (Fourier Transform Infrared) Shimadzu 8400 with a $\mathrm{KBr}$ matrix, ${ }^{1} \mathrm{H}-\mathrm{NMR}$ spectrum (500 MHz) was measured with a Bruker 3000 NMR spectrometer with $\mathrm{CDCl} 3$ solvent. Gas Chromatography-mass spectroscopy (GC-MS) was measured with GC-MS Agilent 19091S-433, Equipment with HP-5 MS capillary column $(30 \mathrm{mx} 0.25 \mathrm{~mm}$, id $0.25 \mu \mathrm{m}$ ) and HP 5972 selective mass detector. GC-MS detection by the electron ionization (EI) method with ionisation energy used was $70 \mathrm{eV}$. Helium is used as a carrier gas with a speed of $20 \mathrm{~mL} / \mathrm{min}$. The injector and MS transfer line are set at a temperature of 150 and $250{ }^{\circ} \mathrm{C}$ respectively, the column temperature is kept at $80^{\circ} \mathrm{C}$ for the initial $3 \mathrm{~min}$, then raised to $325^{\circ} \mathrm{C}$ at a rate of $3^{\circ} \mathrm{C} / \mathrm{min}$. a sample of $2 \mu \mathrm{L}$ was injected manually with split mode.

In a $50 \mathrm{~mL}$ round bottom flask, the mixture of dimedon ( $2 \mathrm{mmol}, 280 \mathrm{mg}$ ) with vanillin (1.1 mmol, $167 \mathrm{mg}$ ) and guanidine as in Figure 1. $\mathrm{HCl}$ (10 mol\%) is refluxed in $10 \mathrm{~mL}$ of ethanol at its boiling point for a specified time variation. After the reaction is finished the mixture is cooled to room temperature and a pale yellow solid is obtained. The solid was recrystallized using a hot ethanol solvent and a pure white compound was obtained. The progress of each stage is monitored by TLC using n-hexane: ethyl acetate (8:2) eluent. The structure of compound produced was confirmed using OR, ${ }^{1} \mathrm{H}-\mathrm{NMR}$ and GC-MS methods.

The resulting compound data are as follows: 3,3,6,6-Tetramethyl-9-(4-hydroxy-3-

methoxy-phenyl) octahydroxanthene, white 
amorphous powder, 91\% yield, IR (KBr) $\left(\mathrm{V}_{\max }, \mathrm{cm}^{-1}\right) 3306(\mathrm{OH}), 3022\left(\mathrm{CH} \mathrm{sp}^{2}\right), 2973$ (CH, sp3), 1753 ( $\mathrm{C}=0$ ), $1662(\mathrm{C}=\mathrm{C}), 1368$ (CH bending), 1140 (C-0), ${ }^{1} \mathrm{H}-\mathrm{NMR}\left(\mathrm{CDCl}_{3}\right)$ (chemical shift, ppm) $1.09(6 \mathrm{H}, \mathrm{s}), 1.12(6 \mathrm{H}$, s), $2.40(8 \mathrm{H}, \mathrm{m}), 3.74(\mathrm{~s}, \mathrm{OCH} 3), 4.64(\mathrm{~s})$, $1 \mathrm{H}), 6.57(\mathrm{dd}, 1 \mathrm{H}, \mathrm{J}=8.4 \& 1.9 \mathrm{hz}), 6.78(\mathrm{~d}$, $1 \mathrm{H}, \mathrm{J}=8.4 \mathrm{~Hz}$ ), $7.24(\mathrm{~s}, 1 \mathrm{H}, \mathrm{J}=1.9 \mathrm{hz}) 11.96$ $(\mathrm{s}, \mathrm{OH})$

\section{Results And Discussion}

This study reports a simple method of transforming vanillin with an efficient route. The stoichiometric ratio between dimedon and vanillin was $2: 1$. But in the reaction 2 mmol of dimedon and $1.1 \mathrm{mmol}$ of vanillin are used in order to achieve a limiting reagent so as to prevent an equilibrium reaction shifting towards the reactants so that the resulting product will be more maximal. In this transformation, guanidine acts as a catalyst base. The catalyst-free transformation reaction carried out for 2 hours in ethanol solvent did not provide a significant amount of product. Following the yield of the transformation of vanillin with dimedon to produce octahydroxanthene with variations in reaction time as Table 1.

Table 1. Yields of compounds resulting from vanillin transformation

\begin{tabular}{cccc}
\hline No & Guanidine Catalyst & Time reaction & Yield $(\% \mathrm{w} / \mathrm{w})$ \\
\hline 1 & - & $120 \mathrm{~min}$ & 5 \\
2 & $10 \% \mathrm{~mol}$ & $15 \mathrm{~min}$ & 46 \\
3 & $10 \% \mathrm{~mol}$ & $30 \mathrm{~min}$ & 78 \\
4 & $10 \% \mathrm{~mol}$ & $60 \mathrm{~min}$ & 91 \\
5 & $10 \% \mathrm{~mol}$ & $120 \mathrm{~min}$ & 80 \\
\hline
\end{tabular}

In the above experiment variations on reaction time with the independent variable amount of catalyst $10 \% \mathrm{~mol}$, solvent $10 \mathrm{~mL}$ ethanol and reflux temperature obtained a maximum yield of $91 \%(\mathrm{w} / \mathrm{w})$ at 60 minutes. Addition of time twice the optimum time turns out to result in lower yields. This is indicated that the compounds formed will be degraded by heat to form other unexpected compounds. 


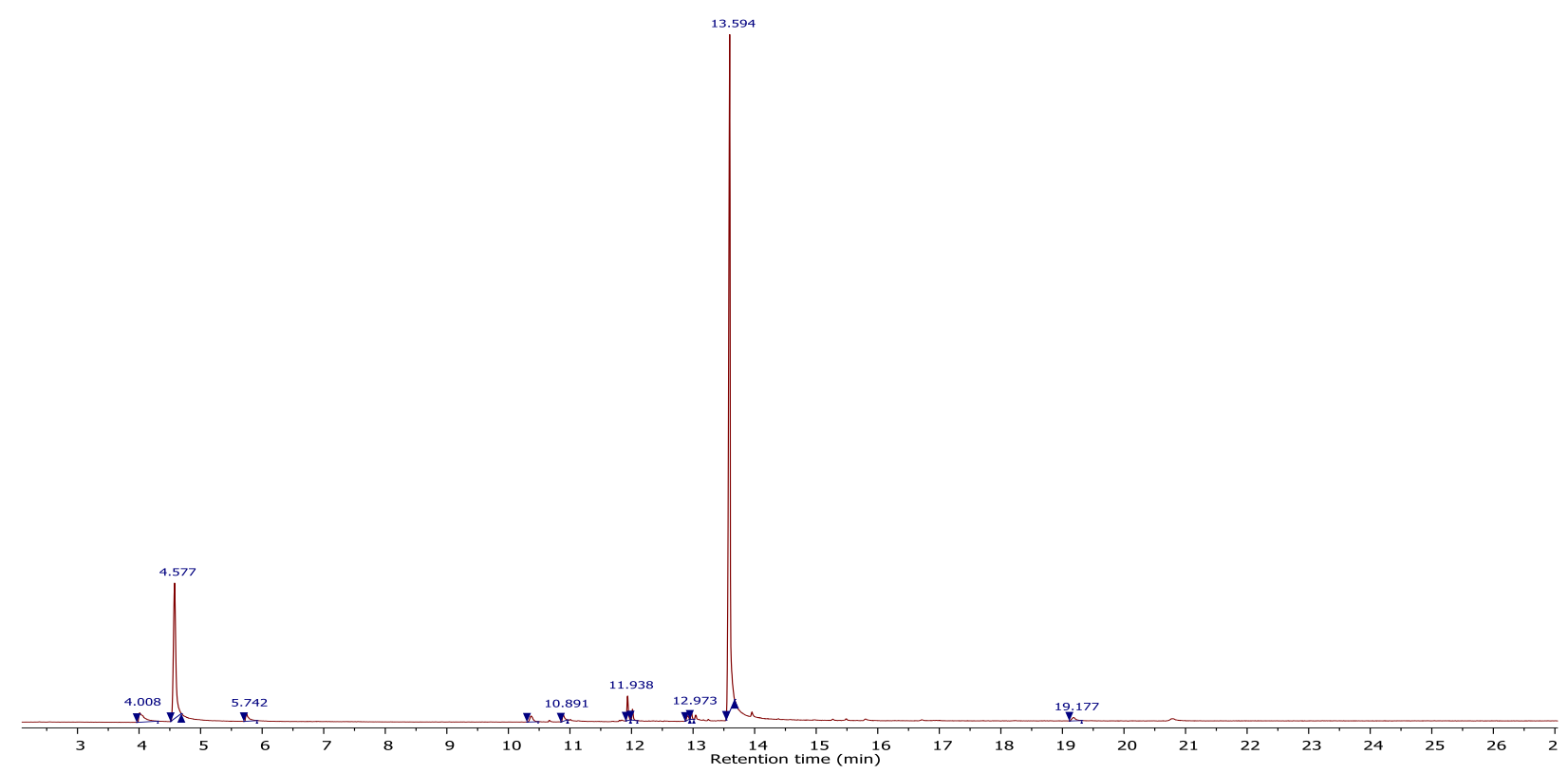

Figure 2. Chromatogram of compounds resulting from vanillin transformation

Confirmation of the structure is done after purity testing using TLC and GC-MS. A single spot obtained from TLC with the UV-254 nm viewer shows that the compound is purely retative. The purity data was corroborated by GC-MS measurements obtained by a chromatogram with a peak with a $96 \%$ percent area at a retention time of 13.59 minutes as in Figure 2. Gas chromatography measurements followed by mass spectroscopy using the $70 \mathrm{eV}$ energy impact ion ionization method do not show the parent peak at $\mathrm{m} / \mathrm{z} 396$. However, $\mathrm{m} / \mathrm{z} 273$ appears indicating the formation of the octahydroxanthene framework (Shanmugam et al, 2004) as described in Figure 3.<smiles>COc1cc([C]2C3=C(CC(C)CC3=O)OC3=C2C(=O)CC(C)(C)C3)ccc1O</smiles><smiles></smiles><smiles>COc1ccccc1O</smiles>

Figure 3. Transformation of compound fragmentation patterns that show the formation of octahydroxyxanthene

Analysis of the alleged structure was followed by ${ }^{1} \mathrm{H}-\mathrm{NMR}$ spectroscopy. In the ${ }^{1} \mathrm{H}-\mathrm{NMR}$ spectrum, seven groups of protons appear that indicate the presence of protons with different groups. $1.09 \mathrm{ppm}$ signal with singlet multiplicity with 12 proton integration shows four methyl groups derived from dimethyl in two dimedone structures incorporated in the transformed compound. This is also strengthened by the $2.40 \mathrm{ppm}$ signal for eight protons from four methylene groups. The specificity of the 
dihydroxantene structure is the $4.64 \mathrm{ppm}$ signal with singlet multiplicity for one proton which is a proton from a neighboring metin $(\mathrm{CH})$ group originating from the reacting aldehyde group. There are groups of aromatic protons with the ABX system namely 6.57 (dd, $1 \mathrm{H}, \mathrm{J}=8.4 \& 1.9 \mathrm{hz}$ ), 6.78 (d, $1 \mathrm{H}, \mathrm{J}=8.4 \mathrm{~Hz}$ ), $7.24(\mathrm{~s}, 1 \mathrm{H}, \mathrm{J}=1.9 \mathrm{~Hz}$ ) originating from the aromatic part of vanillin which is then corroborated with infrared spectrum data that shows the presence of $\mathrm{OH}$ groups at the widening peak with wave number $3306 \mathrm{~cm}^{-1}$.

\section{Conclusion}

This research has successfully transformed vanillin compound with octahydroxanthene compound using guanidine catalyst. The optimization process with time variations obtained an optimum time of 60 minutes with a yield of $91 \%$ on the control variable catalyst amount of $10 \% \mathrm{~mol}$ and ethanol reflux reaction temperature. The resulting compound was easily purified by the recrystallization method with hot ethanol and the structure of the compound was successfully confirmed by the IR spectrum, ${ }^{1} \mathrm{H}-\mathrm{NMR}$ and GC-MS

\section{Acknowledgements}

Thank you to Dr. Anthoni Pardede from the Islamic University of Kalimantan, Banjarmasin for assistance in measuring ${ }^{1} \mathrm{H}$ NMR as well as to Arif ashari from the Sumatran Institute of Technology who helped with the purification process.

\section{References}

Bhat S U, Naiko R A, Mir M A, Bhat R A, Malla M A, Tomar R. . 2016. Synthesis of 14Aryl-14H-dibenzo[a,j]xanthene

Derivatives Using H-Zeolite $\mathrm{A}$ as an Efficient and Reusable Catalyst under Solvent-Free Condition. Hindawi Publishing Corporation Journal of
Materials Volume 2016, Article ID 7908584

Cahyana A H, Abdussalam M, 2018. Synthesis octahydroxanthene using cathalytic $\mathrm{H}_{2} \mathrm{SO}_{4}$ in free solvent condition. AIP Conference Proceedings 2049, 020070 (2018); doi: $10.1063 / 1.5082475$

Dabiri M, Azimi S C, Bazghir A . 2008. Onepot synthesis of xanthene derivatives under solvent-free conditions. Chemical Papers 62 (5) 522-526

Dewick, P. M. 2009. Medicinal Natural Products: A Biosynthetic Approach, 3rd Edition. John Wiley \& Sons, Ltd

Matsjeh, S . 2009. Pemanfaatan bahan alam nabati yang berpotensi sebagai bahan baku sebagai obat. https://repository.ugm.ac.id/ diakses 5 mei 2019

Magar R R, Pawar G T, Gadekar S P, Lande M K. 2018 . An efficient synthesis of 1,8dioxooctahyroxanthenes derivatives using heterogeneus Ce-ZSM-11 Zeolite catalyst. Bulletin of chemical reaction enginering \& catalyst, 13 (3) 2018, 436-446

Moghanian $\mathrm{H}, \quad$ Mobinikhaledi A, Deinavizadeh M. 2014. Efficient, onepot synthesis of xanthene derivatives using boron sulphonic acid as a solid heterogeneous catalyst under solventfree conditions. Res Chem Intermed. DOI 10.1007/s11164-014-1537-5

Risnandar A I, Prabawati S Y. 2019. Sintesis senyawa mentil vanilat dari vanili dan aplikasinya sebagai parfum. Alkimia : Jurnal Ilmu kimia da terapan Vol 3 No 2 
Shanmugam P, Sabastein C, Perumal P T, 2004. Synthesis of fused dihydropirimidinon from cyclic 1,3 dicarbonyl compounds, Indian Journal of Chemistry vol.43B pp 135-140

Sofyaningsih M, Sugiyono, Setyaningsih D. 2011. Vanilin retention and color changes of concentrated vanilla Extract during storage. J.Teknol.dan industri Pangan Vol. XXII no 2 Th 2011 